\title{
Normalcy, justification, and the easy-defeat problem
}

\author{
Marvin Backes ${ }^{1}$
}

\begin{abstract}
Recent years have seen the rise of a new family of non-probabilistic accounts of epistemic justification. According to these views-we may call them Normalcy Views - a belief in $\mathrm{P}$ is justified only if, given the evidence, there exists no normal world in which $\mathrm{S}$ falsely beliefs that $\mathrm{P}$. This paper aims to raise some trouble for this new approach to justification by arguing that Normalcy Views, while initially attractive, give rise to problematic accounts of epistemic defeat. As we will see, on Normalcy Views seemingly insignificant pieces of evidence turn out to have considerable defeating powers. This problem-I will call it the Easy-Defeat Problem-gives rise to a two-pronged challenge. First, it shows that the Normalcy View has counterintuitive implications and, second, it opens the door to an uncomfortable skeptical threat.
\end{abstract}

Keywords Justification · Defeat · Normalcy · Multi premise closure · Lotteries

\section{Introduction}

Many epistemologists have embraced the idea that epistemic justification amounts to something along the lines of high probability. On this popular picture, there exists some epistemic good-making feature-e.g. an agent's total body of evidence or the general reliability of a belief-forming process - and a belief that $\mathrm{P}$ is justified in so far as P's degree of probability, given the relevant good-making feature, is above some threshold required for justification. Let's call this Lockean picture of

Marvin Backes

mb302@st-andrews.ac.uk

1 Arché Philosophical Research Centre, University of St Andrews, 17-19 College Street, St Andrews KY16 9AL, Scotland, UK 
justification, the Threshold View. ${ }^{1}$ For our current purposes we can characterize threshold views by their shared commitment to the following thesis.

Threshold Thesis The belief that $\mathrm{P}$ is justified for $\mathrm{S}$ iff $\mathrm{P}$ is highly probable for $\mathrm{S} .^{2}$

What makes threshold views so popular is that justification is almost universally believed to come in degrees and to be fallible, i.e. to require less than probability 1. With these two commitments in place, there is something very natural about the idea that epistemic justification must amount to something along the lines of high probability. ${ }^{3}$ However, a well-known challenge for threshold views is that they are incompatible with the following intuitively compelling and attractive principle of multi premise closure.

Multi Premise Closure (MPC) If $S$ is justified in believing $\mathrm{p}$ and $\mathrm{S}$ is justified in believing $\mathrm{q} \ldots$ and $\mathrm{S}$ is justified in believing $\mathrm{n}$, then $\mathrm{S}$ is justified in believing the conjunction (p \& q... n).

Threshold views (for any threshold value $t<1$ ) force us to give up (MPC) because they face the problem of risk accumulation: as one begins conjoining individually justified beliefs, the error risk associated with each conjunct accumulates and eventually the probability of the conjunction can fall below the threshold required for justification.

Motivated primarily by the incompatibility of threshold views with (MPC), epistemologists have become increasingly interested in exploring alternatives to the probabilistic picture. The idea is simple: if threshold views of justification are not compatible with (MPC), then maybe relocating the source of epistemic justification to something other than high probability will allow us to avoid this problem.

The perhaps most promising alternative to the probabilistic picture is a new family of views, which I will call Normalcy Views. ${ }^{4}$ Normalcy Views of justification turn their back on probabilistic considerations and instead explain justification in terms of what is normal on one's evidence. Broadly speaking we may characterize Normalcy Views by their shared commitment to the following thesis.

Normalcy Thesis (NT) The belief that $\mathrm{P}$ is justified for $\mathrm{S}$ only if, given S's evidence E, there does not exist a single normal world in which $\mathrm{S}$ falsely beliefs that P.

\footnotetext{
1 Threshold views of justification have been defended by a wide range internalists as well as externalists. For examples, see Goldman (1979), Bonjour (1985: 6), Alston (1988: 269), Moser (1989: 42), Foley (1992), Plantinga (1993: 18), Swinburne (2001), Conee and Feldman (2004: 100), Pryor (2004: 352), Bergmann (2006: ch. 6) and Sturgeon (2008).

2 The Threshold Thesis is essentially a justification analogue of the well known Lockean Thesis, which explains rational belief in terms of rational degrees of belief or credences.
}

Lockean Thesis It is rational for you to believe p just in case it is rational for you to have degree of confidence y in p, where y $>\mathrm{x}$. (Foley 1992: 112).

${ }^{3}$ A similar observation about the apparent naturalness of a probabilistic conception of justification can be found in Smith (2016: 29).

${ }^{4}$ For the two leading versions, see Smith $(2010,2016)$ and Leplin (2009). 
Unlike the Threshold Views, Normalcy Views are able to preserve (MPC) as they avoid the problem of risk accumulation: Since for any belief to be justified there cannot exist a normal world in which the belief is false, there will also be no normal world in which a conjunction of these beliefs is false; After all, a normal world in which the conjunction is false would require a normal world in which one of its conjuncts is false and this possibility is ruled out by Normalcy Views. Furthermore, Normalcy Views are also able to preserve our fallibilist intuitions: a belief can be justified yet false as long as the world in which $\mathrm{S}$ falsely beliefs that $\mathrm{P}$ fails to be normal. This puts Normalcy Views in the unique position of being able to accommodate both (MPC) as well as our fallibilist intuitions. As such it is worth to consider these views in more detail and to subject them to critical scrutiny.

This paper aims to raise some trouble for Normalcy Views by arguing that they give rise to problematic notions of epistemic defeat. In the next section I will briefly present the two leading Normalcy Views: Smith's Normic Support Account and Leplin's Normic Reliabilism. I then argue that both accounts face the same problem of being highly sensitive to defeating evidence, which results in justification being lost much too easily-I will call this the Easy-Defeat Problem. Finally I argue that since the problem is structural in nature there is little hope that other views following (NT) will be able to avoid this problem. In the end it appears that there are good reasons for rejecting the central claim of Normalcy Views: that in order for a belief to be justified it is necessary that there does not exist a single normal world in which $\mathrm{S}$ falsely believes that $\mathrm{P}$.

\section{The two leading proposals}

As presented above, (NT) only provides the general contours, or the modal shape, of a more complete theory. The details of how to best understand the modal constraint proposed by (NT) can be developed in different ways. There are currently two leading proposals on the market.

The first one is due to Martin Smith who recently proposed an account of justification according to which a belief that $\mathrm{P}$ is justified only if the evidence $\mathrm{E}$ normically supports $\mathrm{P}$-i.e. if given ones evidence, $\mathrm{P}$ is true in all the normal worlds. Let's call this the Normic Support Account.

Normic Support Account In order for one to have justification for believing a proposition $\mathrm{P}$, it is necessary that one's body of evidence E normically support $\mathrm{P}$ - it is necessary that all the most normal worlds in which $\mathrm{E}$ is true are worlds in which $\mathrm{P}$ is true. $(2016, \text { p. } 42)^{5}$

\footnotetext{
5 Formally, Smith expresses the account as follows. Let $\mathrm{E} \mathbf{\square} \rightarrow \mathrm{P}$ represent 'E normically supports P' and let $\mathcal{N}_{\mathrm{w}}$ be a function "carrying information about the comparative normalcy of possible worlds from the perspective of w" (Smith 2016: 137). The notion of normic support can now be expressed as follows.
}

Normic Support Account Formal $\mathrm{E} \square \rightarrow \mathrm{P}$ is true at $\mathrm{w} \in \mathrm{W}$ iff either (1) there is a sphere $\mathrm{N} \in \mathcal{N}_{\mathrm{w}}$ such that $\mathrm{N}$ is E-permitting and every E-world in $\mathrm{N}$ is a P-world or (2) there is no sphere $\mathrm{N} \in \mathcal{N}_{\mathrm{w}}$ such that $\mathrm{N}$ is E-permitting. (137). 
As we can see, in the Normic Support Account the modal constrained presented by (NT) is cashed out via a specific notion of evidential support called normic support.

A very different way of developing (NT) can be found in recent work by Jarrett Leplin. According to Leplin a belief is justified only if it was reliably produced; where reliably produced means produced using a belief-forming method that is perfectly reliable under normal conditions. More precisely, for Leplin a belief is justified only if (i) it was produced by a method that is perfectly reliable under normal conditions and (ii) the believer has no reason to believe that conditions are abnormal (2009: 43). ${ }^{6}$ In spelling out what it means for a belief-forming method to be perfectly reliable, Leplin draws on modal considerations inspired by Nozick's notion of sensitivity. According to Leplin, "[a] method of belief-formation is reliable if it would not produce or sustain false beliefs under normal conditions. If a belief is produced or sustained by a reliable method under normal conditions, then were this belief to have been false, the process would not, under those conditions, have produced or sustained it" (35). For our purposes, Leplin's account of justification (henceforth Normic Reliabilism) might be presented as follows.

Normic Reliabilism In order for $\mathrm{S}$ to have justification for believing a proposition $\mathrm{P}$, it is necessary that S's belief was reliably produced-it is necessary that (i) the belief that $\mathrm{P}$ was produced by a belief-forming method $\mathrm{M}$ that would not, in any normal world, produce the belief that $\mathrm{P}$ if $\mathrm{P}$ were false and (ii) that the believer has no reason to believe that conditions are abnormal.

We can see that there are considerable differences in how the two leading Normalcy Views develop (NT). While the Normic Support Account accommodates the modal constraint proposed by (NT)'s via a special notion of evidential support, Normic Reliabilism accommodates (NT)'s modal constraint via a particular notion of reliable belief-production. ${ }^{7}$ But, we will see that despite these differences both accounts turn out to be problematic.

In the next two sections I argue that the Normic Support Account is unsatisfactory because it gives rise to an account of epistemic defeat on which beliefs lose their justificatory status much too easily. I then argue that the same problem befalls Normic Reliabilism.

\footnotetext{
${ }^{6}$ Leplin argues for a third condition, namely that the belief-forming method must be used intentionally. This condition is intended to address the Generality Problem. Since I am not concerned with this issue here I will, in the interest of simplicity, ignore this detail.

7 Interestingly, despite the considerable differences between Smith's Normic Support Account and Leplin's Normic Reliabilism it is very difficult to think of a case in which the two theories make diverging predictions. As an interesting working hypothesis it might be suggested that the two theories are extensionally equivalent.
} 


\section{Normic support}

According to the Normic Support Account a belief is justified only if it is normically supported by the evidence. What does it mean for a body of evidence to normically support a proposition?

Informally, a body of evidence E normically supports a proposition $\mathrm{P}$ only if, given the evidence E, it would call for special explanation if $\mathrm{P}$ turned out to be false (Smith 2016: 40). To illustrate, consider some paradigmatic instances of justified beliefs. For example, suppose a subject wrongly forms a belief based on perceptual evidence (e.g. that the car in front of her is red). Smith suggests that this case would call out for a special explanation; some mitigating or interfering circumstances must have obtained to explain why a belief based on perception would fail to be true. Such circumstances might include hallucinations, unfortunate lighting, or deception by a malevolent demon, etc. Similar considerations will of course apply to beliefs based on testimony or memory. Cases in which a belief based on testimony turns out to be false would require some sort of special explanation, e.g. intentional deception by the testifier, a testifier misremembering the facts, mishearing by the receiver, etc. Informally then, for a belief to be normically supported by the evidence, it has to be the case that if the belief turned out to be false, some special explanation would be required.

To turn the notion of normic support into a more formal notion, Smith ties the notion of 'calling for an explanation' to the notion of normality. Events that are normal, so the thought goes, do not call for special explanations, while events that are abnormal do call for special explanations. This allows Smith to provide an analysis of 'normic support' in terms of normal possible worlds. ${ }^{8}$ Beliefs that are normically supported by the evidence will normally be true-i.e. they will be true in normal worlds. Smith captures this idea in the following modal account of normic support:

Normic Support Modal A body of evidence E normically supports a proposition $\mathrm{P}$ just in case $\mathrm{P}$ is true in all the most normal worlds in which $\mathrm{E}$ is true (Smith 2016: 42). ${ }^{9}$

\footnotetext{
${ }^{8}$ More precisely, 'calling for an explanation' becomes a function carrying information about the comparative normalcy of possible worlds.

9 In order to get the modal account of normic supports off the ground, we need to grant that worlds can be ranked according to their comparative normalcy. Smith (2016: 42) is explicit about this assumption and I will not challenge it here. In a recent review of Smith's (2016) book, Anderson (2017) put pressure on this claim by suggesting that Smith's analysis of the notion of normic support is not sufficiently precise to convince us that comparative normalcy rankings are indeed possible; "The main shortcoming of the book is that the core notion is not given sufficient analysis. Normic support is, prima facie, an intuitive notion. Unfortunately, Smith leaves too much to our intuitive grasp... a detailed account of what the notion could do for us is inadequate without a solid grasp of the notion itself." While this may be a good objection, here is something we can say in reply. It is widely accepted that for any given world we can determine what the close or relevantly similar possible worlds are. In other words, it is widely assumed that worlds can be ranked according to their comparative similarity or closeness-accounts of sensitivity (Nozick 1981), safety (Sosa 1999; Williamson 2000), and epistemic luck (Pritchard 2005) all rely on this assumption. However, it is not at all clear that we have a less intuition based or more principled method for making these types of comparative judgments. As a result, I am inclined to think that we should be charitable and grant Smith the assumption that worlds can be ranked according to their comparative normalcy.
} 
This account of normic support combined with the claim that a belief is justified only if it is normically supported by the evidence yields the full Normic Support Account, according to which a belief in $\mathrm{P}$ is justified for $\mathrm{S}$ only if, given $\mathrm{S}$ 's evidence $\mathrm{E}$, there exists no normal world in which $\mathrm{E}$ and not-P obtain together. More informally we might say that one is justified in believing $\mathrm{P}$ only if one's evidence does not contain any information that would explain why one might falsely believe that $\mathrm{P}$.

At this point it is worth pointing out an important feature of the Normic Support Account: whether a belief is normically supported by the evidence is logically independent of P's degree of probability. In other words, the two notions-normic support and high probability - come apart. This turns out to be less mysterious than it may initially appear. Consider the belief that one's ticket in a very large lottery is going to lose-while the belief is highly probable, it wouldn't call for a special explanation if it turned out to be false. Hence, lottery beliefs and other beliefs based on purely statistical evidence fail to be justified on the Normic Support Account. ${ }^{10}$ These considerations point towards a more general consequence of the Normic Support Account, namely that it is possible for a belief to be overwhelmingly probable on the evidence and yet fail to be justified. ${ }^{11}$ As we will see this insensitivity to probabilistic considerations will turn out to be problematic for the Normic Support Account.

\section{The easy-defeat problem}

\subsection{An initial skeptical worry}

One might worry that denying the justificatory status of lottery beliefs, or beliefs based on statistical evidence more generally, exposes the Normic Support Account to a skeptical threat. After all, haven't Vogel $(1990,1999)$ and Hawthorne (2004) given us compelling reasons to think that many of the propositions we believe entail lottery propositions? If lottery propositions fail to be justified on the Normic Support Account, and Hawthorne and Vogel are correct that many ordinary beliefs entail lottery propositions, then the Normic Support Account is threatened to be undermined by skeptical worries.

To make this worry more concrete, consider the following examples.

(a) That Donald Trump is the current president of the United States entails that Donald Trump did not suffer from fatal heart attack within the last few minutes.

\footnotetext{
${ }^{10}$ Since many have the intuition that the belief that one will not win the lottery is justified, we could consider this a strike against the Normalcy View. However, I am not interested in the justificatory status of lottery beliefs here.

11 Likewise it is possible for a belief to be highly improbable on the evidence and yet to be normically supported by the evidence. One example comes from Smith's analysis of the preface paradox. Smith argues that the author's belief that the book is error-free, despite being highly improbable, can nevertheless be normically supported by the evidence.
} 
(b) That I will be able to cook dinner later entails that there will not be a power outage in my neighborhood.

(c) That I am correct in believing that the New York Knicks beat the Boston Celtics last night after reading it in the newspaper entails that the newspaper did not misprint the scores.

Note that these entailments appear relevantly similar to lottery propositions in that they are (a) statistically very likely but (b) don't have any special evidence in their support. Since the Normic Support Account denies that high probability is sufficient for justification, one might worry that it will end up having to deny that we can justifiably believe that Donald Trump is the current president of the United States, that one will be able to cook dinner later, or that the New York Knicks beat the Boston Celtics last night. Similar lottery-like entailments can of course be found for almost any propositions. How can proponents of the Normic Support Account respond to this skeptical challenge?

Fortunately, Smith offers what I take to be a compelling response. In short, he tries to break the supposed symmetry between these lottery-like entailment proposition and genuine lottery propositions. The thought is the following: while for genuine lottery beliefs, e.g. the belief that my lottery ticket is going to lose, it would not call for a special explanation if the belief turned out to be false, for lottery-like propositions it would call for a special explanation if they were false.

My response to the skeptical problem is perhaps not as definitive as one might wish-but I want to suggest that the analogy between genuine lottery propositions and lottery-like propositions is simply not as close as Hawthorne suggests.... If the president died within the last five minutes, or there is a power outage in my neighborhood, or the scores in the newspaper are in error, there would have to be some explanation as to how such things came about... This is a significant disanalogy with genuine lottery propositions (Smith 2016: 57-58).

A different way of making Smith's point is to say that while for genuine lottery propositions, given the evidence, there always exists a normal world in which one's belief is false, for lottery-like propositions such as the ones considered above, there does not exist a normal world in which they are false. As a result one would lack justification for believing that one's lottery ticket is a loser but one would be justified in believing that Trump has not recently suffered a fatal heart attack and that he is the current president of the United States. Thus, the skeptical threat of traditional Hawthorne/Vogel lottery variants is avoided.

However, in what follows I argue that the notion of defeat that falls out of the Normic Support Account gives rise to a new skeptical challenge-one which is not so easily avoided.

\subsection{The easy-defeat problem}

Recall that according to the Normic Support Account, a belief that $\mathrm{P}$ is justified only if the evidence E normally supports $\mathrm{P}$, i.e. only if all of the worlds in which $\mathrm{E}$ is true 
are worlds in which $\mathrm{P}$ is true. It follows that justification is defeated as soon as a piece of evidence establishes the existence of a single normal E \& not-P world. In these cases it would no longer call for an explanation if the belief turned out to be false, because a world in which $\mathrm{P}$ is false is compatible with one's body of evidence. From this we can construct the following account of Normic Defeat.

Normic Defeat (ND) S's justification for believing P is defeated if given a new piece of evidence $\mathrm{D}$, there exists at least one normal world in which $\mathrm{E}$ is true and $\mathrm{P}$ is false.

(ND) is a non-probabilistic account of defeat and the fact that non-probabilistic accounts of justification will generate non-probabilistic accounts of defeat is not surprising. However, non-probabilistic accounts of defeat like (ND) do have surprising consequences: since the Normic Support Account is entirely insensitive to probabilistic considerations there is nothing that prevents minimal probability possibilities, i.e. possibilities that are overwhelmingly improbable, from acting as defeaters. As soon as a piece of evidence establishes the existence of just one normal E \& not-P world, no matter how remote the probability that this world is the actual world, justification for $\mathrm{P}$ is lost.

In this regard, the normic support framework departs considerably from that of standard threshold accounts on which defeating evidence needs to be sufficient to bring a belief's degree of probability below the threshold required for justification. According to (ND) however, for a piece of evidence to defeat P's justificatory status it is not necessary that it makes the possibility of being in an E \& not-P world even remotely probable; all it needs to do is introduce a single $\mathrm{E} \&$ not-P world into the sphere of most normal E worlds.

This should provide some initial reason for concern. If all that is required for justification to be defeated is for some evidence to introduce the existence of just one normal E \& not-P world, no matter remote the probability that this world is the actual world, then one might worry that defeat simply comes too easily on the normalcy view. This problem-let's call it the Easy-Defeat Problem-has some unattractive and costly consequences.

We can illustrate the Easy-Defeat Problem by slightly augmenting traditional Vogel/Hawthorne style lottery variants.

Allergy Helen is allergic to peanuts. She goes to a café and orders a brownie labeled 'peanut free'. Based on this Helen is justified in believing P, that the brownie is safe to eat. On the Normalcy View this entails that there does not exist a single normal world in which $\mathrm{Q}$, the brownie has been contaminated by something containing peanuts. After ordering the brownie Helen sees a news paper headline that reads D, international flour supplier admits to having accidently put 1 bag of peanut-contaminated baking flour into circulation.

Allergy differs from standard lottery-like cases in that it does not just raise to salience the plain possibility of error, i.e. that there is always a small chance that even a brownie labeled 'peanut-free' might turn out to be contaminated. Instead it goes one step further and provides, through additional evidence $\mathrm{D}$, an explanation for why Helen's belief that her brownie is safe to eat may be false. It is this 
additional piece of evidence that makes it an augmented case of its more traditional counterparts. I assume that in Allergy we would still want to say that Helen is justified in believing that her brownie is safe to eat and that D is not sufficient to defeat the justificatory status of Helen's belief; after all we do not ordinarily assign such seemingly negligible evidence this kind of defeating power. However, as I will argue now, the Normic Support Account will not deliver this result.

In order for Helen to be justified in believing $\mathrm{P}$, that her brownie is safe to eat, there must not exist a single normal world in which Helen, given her total body of evidence, falsely beliefs that P. Since a world in which Q is true would be such a world, in order for Helen's belief in $\mathrm{P}$ to be justified there cannot exist a single normal world in which $\mathrm{Q}$ obtains, i.e. there cannot exist a single normal world in which Helen's brownie has been contaminated. An important question then is whether given Helen's total body of evidence E, which now includes D, the information about the 1 contaminated bag of flour, there exists at least one normal world in which Helen's brownie is contaminated.

It seems plausible that such a world does exist-this of course is the world in which the 1 bag of contaminated flour just so happened to end up in the café at which Helen just ordered her brownie. Given Helen's evidence there seems to be nothing strange or abnormal about this possibility. In the end the bag of contaminated flour must have ended up somewhere and there does not appear to be anything particularly abnormal about it having ended up in the café where Helen just bought her brownie than in any other café. It might of course be less probable that it would end up in some café rather than others-after all, some cafes will go through a lot more flour than others-but recall that the normalcy account ignores probabilistic considerations of this kind. So, given Helen's total body of evidence it seems plausible that there does exist a normal world in which Helen's brownie has been contaminated. As a result, Helen's belief that her brownie is safe to eat fails to be normically supported by the evidence and subsequently fails to be justified on the Normic Support Account. A problematic prediction.

It is of course easy to generate more of these cases. Consider the following example.

Lightning A few days ago Helen has made plans with her friend Bob to visit him in Oxfordshire next weekend. Based on this Helen is justified in believing P, that she will see Bob next weekend. On the Normalcy View this entails that there does not exist a single normal world in which Q, Bob has been fatally struck by lightning. As Helen is thinking about her upcoming trip to Oxfordshire she reads a newspaper headline stating D, man in Oxfordshire fatally struck by lightning.

The worry is the same as in the previous case. In light of $\mathrm{D}$, a seemingly negligible piece of evidence, it appears that Helen's belief is no longer normically supported by the evidence. Why? Consider the following question: Given Helen's total evidence, does there exists at least one normal world in which her belief that she will see Bob next weekend is false? Again it seems plausible that such a world exists - this of course is the world in which the man fatally struck by lightning just happened to be Bob. Given that Helen knows that a man was fatally struck by lightning, there does not appear to be anything terribly abnormal about the possible 
world in which this person was Bob. Again, it is of course highly unlikely that Bob was struck by lightning, but recall that this is irrelevant on the Normic Support Account-what matters is whether it would be abnormal on the evidence, and that it ultimately isn't. Thus, we have good reasons for thinking that after learning D Helen's belief that the she will see her friend Bob next weekend is no longer normically supported by the evidence and subsequently fails to be justified. Another problematic result.

These two cases illustrate a general structural problem with the Normic Support Account-namely that negligible pieces of evidence can have serious defeating power. The heart of the Easy-Defeat Problem, to reiterate, is that according to the Normalcy View the introduction of a single normal E \& not-P world is sufficient for defeat - no matter how remote the probability that it is the actual world. Additional cases illustrating this problem can easily be generated using the following recipe: First, chose a proposition $\mathrm{P}$ that is justified for $\mathrm{S}$. Next, chose a proposition $\mathrm{Q}$ that is entailed by P. Finally, introduce a new piece of evidence D, such that (i) D provides an explanation for why $Q$ might obtain and (ii) $Q$ remains so overwhelmingly improbable that we judge D insufficient to defeat P's justificatory status.

\subsection{The easy-defeat problem's implications}

Why is the Easy-Defeat Problem bad news for the Normic Support Account? First, as the cases above illustrate, the problem of easy defeat shows that the account has counterintuitive implications. For instance, in Allergy we would not ordinarily consider the fact that 1 bag of contaminated flour has accidentally been put into circulation sufficient to defeat Helen's justification for believing that her brownie is safe to eat. We might accept that in light of such evidence Helen should slightly lower her confidence in $\mathrm{P}$, but we would not accept that the evidence is anywhere near sufficient for defeat. More generally, we do not tend to assign defeating powers to highly improbable error possibilities. A plausible explanation for our reluctance to accept the normalcy view's defeat predictions might be that we generally expect an undermining defeater to make the falsity of a belief sufficiently probablemerely establishing that it would not be entirely abnormal if the belief turned out to be false seems to set the bar for defeat problematically low. Thus, if the Normic Support Account is to be understood as a descriptive account, i.e. an account that adequately captures our ordinary concept of justification, then the account fails; for in at least some cases - those involving low probability defeaters-its predictions systematically diverge from our ordinary judgments. If on the other hand the Normic Support Account is supposed to be prescriptive, i.e. an account about how we should think about justification rather than how we do think about justification, then one would have to argue that the account's counterintuitive easy-defeat predictions are virtues rather than vices of the view. Making this conclusion palatable however will not be an easy task.

Alternatively, we can give a diagnosis of the problem in terms of Ichikawa's notion of stinginess. In recent work, Ichikawa (2014) made explicit what is often taken for granted, namely that one condition any plausible theory of justification needs to satisfy is that it is not 'too stingy'. According to Ichikawa, an account of 
justification is too stingy if, "it denies justificatory status to too many beliefs that are intuitively justified" (186). What the Easy-Defeat Problem demonstrates is that by predicting defeat too readily the Normic Support Account systematically violates this plausible stinginess constraint.

To make matters worse, there are good reasons for thinking that instances of the Easy-Defeat Problem, like Lightning or Allergy, are not far-fetched isolated cases, but that we find ourselves in these kinds of epistemic situations frequently. This is the case because we frequently come across information that provides a possible explanation for why many of our beliefs may be false. Put differently, we frequently come across information that introduces, for a considerable number of beliefs, a small number of normal worlds in which the belief is false. Just consider the ubiquity of information like the following: 'Devastating fire in New York City apartment', 'Contaminated eggs discovered in supermarkets', 'Fatal hit and run in central London', 'Shark attack off the coast of Australia', 'Plane crash over the Atlantic, or 'In very rare cases (1 in 100,000) this medication has been linked to anxiety and depression'. Since evidence of this kind provides an explanation for why one might falsely belief that one still has an apartment in New York City, that one's friends who live in London are alive and well, that one's cousin who lives in Australia and enjoys an occasional swim has not fallen victim to a shark attack, or that ones allergy medication will make one feel better rather than worse, these beliefs would fail to be justified on the Normic Support Account. Moreover, one would also lose justification for any proposition entailed by these beliefs. So, the epistemic consequences of the Easy-Defeat Problem are much more expansive and far-reaching than initially thought. Of course the falsity of any of these beliefs is highly improbable, but recall that the Normic Support Account is not sensitive to probabilistic considerations. Thus, the Normic Support Account combined with the fact that we frequently acquire evidence that provides an explanation for why some of our beliefs might be false entails that we lack justification for a great many beliefs that we ordinarily take to be justified.

The Easy-Defeat Problem then poses a two-pronged challenge against the Normic Support Account. In a first instance it gives rise to straightforward counterexamples to the view. And secondly, it reintroduces skeptical worries, which Smith tried to avoid.

\subsection{Anticipating a response}

A perhaps initially compelling response to the Easy-Defeat Problem might be to deny that in cases like Allergy, Lightning, or any of the other examples, there really does exist a normal world in which these beliefs are false-let's call this the Denial Strategy. However, I think there are good reasons to be skeptical about this strategy. Recall that within the normalcy framework the notion of normality is explained via the notion of 'calling for explanation': for any proposition $\mathrm{P}$ and body of evidence $\mathrm{E}$, there does not exist a normal world in which $\mathrm{P}$ is false, only if, given $\mathrm{E}$ it would require an explanation if $\mathrm{P}$ were false. Since in Allergy, Lightning, and the other examples we considered, the evidence does contain an explanation for why the relevant belief that $\mathrm{P}$ may be false-after all, in both cases, $\mathrm{D}$ provides a reason for 
thinking (or suspecting) that P may be false-it seem natural to assume that in these cases it would no longer call for a explanation if $\mathrm{P}$ turned out to be false. The principle underlying this thought is the following.

Explanation If one's body of evidence E contains an explanation for why P may turn out to be false, then it would no longer call for explanation if $\mathrm{P}$ turned out to be false.

So, if we accept Explanation, then in Allergy, Lightning, etc., there does exist a normal world in which $\mathrm{P}$ is false. This means that proponents of the Denial Strategy will need to reject Explanation. Explanation however seems very plausible and it is difficult to see on what grounds one might deny it. In any case, until a convincing argument against Explanation has been produced the Denial Strategy does not look like a promising response to the Easy-Defeat Problem. ${ }^{12}$

In the next two sections I consider the second leading Normalcy View-viz. Leplin's Normic Reliabilism - and whether it is able to avoid the Easy-Defeat Problem. Ultimately I conclude that it cannot.

\footnotetext{
${ }^{12}$ I thank an anonymous referee for the interesting observation that Explanation may have the unintended, and perhaps problematic consequence, of not just explaining why, on the Normic Support Account, we lack justification in easy defeat cases like Lightning and Allergy but that it may also provide reasons for thinking that we lack justification in lottery-like cases discussed earlier.

The reviewer considers the following lottery-like case. Suppose I am justified in believing P, that I will cook dinner tonight. On the Normic Support Account this entails that I also need to be justified in believing $\mathrm{Q}$, that there will not be a power outage tonight. Initially, we may think that this is unproblematic, because if $\mathrm{Q}$ turned out to be false and there was in fact a power outage tonight, then this would be abnormal or call for explanation. However, many of us who are justified in believing Q will also be justified in believing $\mathrm{R}$, that sometimes trees fall on power lines and cause power outages. At this point, the referee suggests that one might think that $\mathrm{R}$ provides an explanation for why $\mathrm{Q}$ may turn out to be false. If this analysis is correct, then according to Explanation it would no longer call for a special explanation if Q was false and subsequently $\mathrm{Q}$ as well as $\mathrm{P}$ - since $\mathrm{P}$ entails Q - would fail to be justified on the Normic Support Account. This result would not just be bad news for the Normic Support Account, as lottery-like cases would present a more serious objection to the Normic Support Account than initially thought, but it would also mean that there is a tension between Explanation and the previous concession that the Normic Support Account can straightforwardly deal with the skeptical threat posed by lottery-like scenarios (Sect. 4.1). How can this tension be dissolved?

Even though Smith never gives a detailed analysis of the notion of calling for an explanation or what it is to have an explanation for something - that was Anderson's (2017) primary criticism of the Normic Support Account (see footnote 9)-it seems there is room to plausibly deny that $\mathrm{R}$ does in fact provide an explanation for why Q may be false. Here is how we may motivate this position in a way that I take to be in line with how Smith seems to think about these cases. In lottery-like cases-like the one suggested by the reviewer-the subject lacks any specific (or positive) evidence for thinking that in this instance their belief may actually be false. Put differently, in lottery-like cases the subject lacks any reason for thinking that the disobliging environmental conditions, which would make them falsely believe that $\mathrm{P}$, may actually obtain. In this regard lottery-like cases differ from easy-defeat cases, in which D provides a specific reason for thinking (or suspecting) that Helen's belief that $\mathrm{P}$ may be false, or that the disobliging environmental conditions that would make her falsely believe that $\mathrm{P}$ may actually obtain. Hence, it seems that we can reasonably deny that $\mathrm{R}$, on its own, provides an explanation for why $\mathrm{Q}$ may be false.

Acknowledging Smith's (2016: 57) remark that his response to the skeptical threat posed by lotterylike cases is not as definitive as one might wish, I think that this is a prima facie plausible and charitable way of thinking about explanations that would (1) preserve the idea that the Normic Support Account is compatible with justification for lottery-like propositions and (2) dissolve the alleged tension between Explanation and justification in lottery-like propositions.
} 


\section{Normic reliabilism}

Recall that according to Leplin, a belief is justified only if it was formed by a method that is perfectly reliable under normal conditions and one has no reason to believe that conditions are abnormal. To see what he has in mind, consider again some paradigmatic instances of justified beliefs. If a belief based on perception were to be false, then, so the thought goes, under normal conditions perception would not have produced the belief-hence, the belief is prima facie justified. What does it mean for conditions to be normal according to Leplin?

Unlike Smith, who cashes out normalcy via a metaphysical relation (the 'calling for an explanation' relation) between a body of evidence and a proposition, Leplin explains normalcy in terms of the conditions we naturally presuppose when using certain belief forming methods: "conditions normal for a method are conditions typical or characteristic of occasions and environments in which the method is usable or applicable" (37). For instance, in cases of perception, we presuppose the absence of trick mirrors, barn facades, and deceptive lighting. Likewise, in cases of testimony we must presuppose the sincerity of the testifier, proper hearing, etc. (40). One could of course easily extend this list of natural presuppositions to include the absence of sudden power outages, barn facades, peanut-contaminated baking flour, dubious pills, etc. Importantly, it is these natural presuppositions which ensure that our beliefforming methods are perfectly reliable. This explains why, besides requiring a beliefforming method to be perfectly reliable under normal conditions, justification also requires that the believer has no reason for believing that conditions are abnormal, i.e. that any of the natural presuppositions are violated; for in abnormal conditions a method's perfect reliability across modal space is no longer guaranteed.

In what follows I will argue that Normic Reliabilism, like the Normic Support Account, faces the problem of easy defeat.

\section{The easy-defeat problem strikes again}

\subsection{Lottery skepticism}

One unsurprising consequence of Normic Reliabilism is that like the Normic Support Account it denies the justificatory status of beliefs based on purely statistical evidence, e.g. lottery beliefs. After all, in the case of lotteries for instance one knows that the method by which one comes to believe that one's ticket is a loser is not perfectly reliable; in a world in which one happens to hold the winning ticket one would nevertheless believe that one's ticket is a loser. This once again raises the issue of Hawthorne/Vogel style lottery skepticism: If Normic Reliablism denies justification in lottery propositions but many ordinary beliefs entail lottery propositions, then hardly any of our beliefs would be justified. However, like Smith, Leplin offers a response to the standard Hawthorne/Vogel skeptical challenge: Leplin, like Smith, denies the symmetry between genuine lotterypropositions and propositions that are merely lottery-like. While Smith distinguishes 
genuine lottery propositions from lottery-like propositions via the notion of "calling for an explanation', for Leplin the relevant difference is that in genuine lottery cases it is guaranteed that the employed belief-forming method will produce a false belief, while in lottery-like case there is no such guarantee (2009: 104). So, while in genuine-lottery cases we know that there exists a possible world in which we falsely belief that our ticket is a loser, the belief-forming method that produce lottery-like beliefs (e.g. that Donald Trump has not recently suffered a heart attack) may well be perfectly inerrant across modal space. For this reason we lack justification for believing genuine lottery proposition while beliefs in lottery-like proposition can be justified. So, traditional Hawthorne/Vogel lottery skepticism is avoided. However, as we will see, Normic Reliabilism too is committed a notion of epistemic defeat on which seemingly irrelevant pieces of evidence are sufficient for defeat. Again this gives rise to a new skeptical threat.

\subsection{The easy-defeat problem returns}

Recall that according to Normic Reliabilism, for a belief to be justified it is necessary that it is reliably produced. And a belief is reliably produced only if it is produced by a belief-forming method $\mathrm{M}$ that is perfectly reliable under normal conditions and the believer has no reason to believe that conditions are abnormal. It follows that the justificatory status of a belief is defeated as soon as the agent has reason for believing that conditions are abnormal. This is the case because under abnormal conditions, i.e. when any of the presuppositions that ensure a method's perfect reliability are violated, a method's perfectly reliability across modal space is no longer guaranteed. These considerations give rise to the following account of defeat for Normic Reliabilism.

Normic Reliabilism Defeat (NRD) S's justification for believing P is defeated if, given a new piece of evidence $\mathrm{D}$, the believer has reason for believing that conditions are (or were) abnormal-i.e. if the believer has reason for believing D and D violates any of the presupposition which ensure that the belief-forming method $\mathrm{M}$ which produced $\mathrm{P}$ is (or was) perfectly reliable across modal space.

Note the strength of the account. Since Normic Reliabilism demands nothing short of perfect reliability, having reason to believe that any of the reliability ensuring presuppositions has been violated is sufficient for defeat-even if the belief-forming method remains highly reliable. More precisely, justification is defeated according to (NRD) if one has reason to believe that there exists just a single world in which the method would produce or sustain a false belief. This gives rise to the same concerns previously raised for the Normic Support Account: Seeing that the account is entirely insensitive to probabilistic considerations, nothing prevents possibilities that are overwhelmingly improbable from having serious defeating powers. This of course is just the Easy-Defeat Problem all over again. ${ }^{13}$

\footnotetext{
13 For a brief discussion about Leplin's requirement of perfect reliability perhaps being too strict, see Christensen (2007).
} 
To illustrate, consider what normic reliabilism would predict in response to the augmented lottery variants considered earlier. In Allergy, Helen formed the belief that the brownie is safe to eat based on the fact that it was clearly labeled 'peanutfree'. Let's assume that under normal conditions this belief forming method is perfectly reliable and one of the natural presuppositions that ensures Helen's method is reliable is something along the lines of, 'brownies labeled peanut-free will not be contaminated'. ${ }^{14}$ However, in Allergy Helen has reason to believe that this presuppositions has been violated or that conditions are abnormal: Knowing that there is a bag of contaminated flour in circulation gives Helen reason to believe that her belief-forming method is no longer perfectly reliable or inerrant across modal space. Thus, in Allergy Helen would lack justification for believing that her brownie is safe to eat. The same considerations apply mutatis mutandis to Lightning. In order for Helen's belief forming method (whatever it may be in this case) to be perfectly reliable, we must presuppose that people do not normally get struck by lightning. However, the evidence D, that a man in Oxfordshire has been fatally struck by lightning provides reason to believe that in this case the presupposition has been violated, i.e. that conditions are abnormal; for D provides reason to believe that Helen's belief forming method is no longer perfectly reliable across modal space. Helen will falsely belief that she will see her friend Bob next weekend in the world in which Bob happened to be the man in Oxfordshire who was struck by lightning. Hence, Helen's belief that she will see Bob next weekend fails to be justified on Leplin's account. The Easy-Defeat Problem has returned.

Recall that the problem of easy defeat presents a two-pronged challenge. First it exposes Normic Reliabilism to straightforward counterexamples in which the justificatory status of beliefs ordinarily take to be justified is denied. And second it opens the door to skeptical a skeptical threat: Normic Reliabilism combined with the fact that we frequently acquire reasons for believing that our belief-forming methods are not perfectly reliable across modal space, yields the unpalatable conclusion that justified beliefs are a lot more scarce than we ordinarily think.

As we have seen, the two leading Normalcy Views-the Normic Support Account and Normic Reliabilism - both face the problem of easy defeat. On both accounts insignificant pieces of evidence turn out to have considerable defeating powers. This makes the accounts overly stingy, leads to counterexamples, and exposes them to skeptical threats, which both Smith and Leplin were hoping to avoid. Is there a way around the Easy-Defeat Problem? In the next section I propose modifications to the two accounts that would allow them to avoid the Easy-Defeat Problem. However, we will see that the required modifications will fail to save the accounts.

\footnotetext{
${ }^{14}$ Leplin acknowledges that it is difficult to specify exactly the conditions under which a certain belief forming method is perfectly inerrant (41). This difficulty becomes apparent here, for it is not at all clear how the content of the relevant presupposition should be formulated. Considering that these presuppositions play a crucial role in Leplin's theory, we might worry that without a method for specifying their content his account remains somewhat incomplete. However, for current purposes I will ignore any difficulties surrounding this issue.
} 


\section{Can the easy-defeat problem be avoided?}

What got the Normic Support Account into trouble is that in order for a belief in P to be justified, P must be true in all normal E worlds. As far as I can see the only way to avoid the problem of easy defeat is to weaken the notion of normic support so that it can accommodate a small number of normal worlds in which $\mathrm{P}$ is false. $\mathrm{A}$ straightforward way of achieving this goal would be to concede that in order to be normically supported by the evidence a belief that $\mathrm{P}$ must be true not in all but only in nearly all normal E worlds. Weakening normic support's modal strength in this way yields the following Weak Normic Support Account.

Weak Normic Support Account (WNSA) In order for one to have justification for believing a proposition $\mathrm{P}$, it is necessary that one's body of evidence $\mathrm{E}$ normically support $\mathrm{P}$ - it is necessary that nearly all of the most normal worlds in which $\mathrm{E}$ is true are worlds in which $\mathrm{P}$ is true.

Similarly, what gets Normic Reliabilism into the problem of easy defeat is that in order for a belief to be reliably produced it is necessary that (i) the belief-forming method is perfectly reliable under normal conditions, and that (ii) the believer has no reason to believe that conditions are abnormal. As we have seen (ii) can easily be violated by seemingly insignificant pieces of evidence because according to the Normic Reliabilism one has reason to believe that conditions are abnormal as soon as one has reason to believe that any of the presuppositions that ensure a belief forming method's perfect reliability across modal space have been violated. To avoid this problem we can weaken (ii) so that if the believer has reason to believe that conditions are abnormal justification can be retained if the believer also has reason to believe that the relevant belief-forming method remains highly reliable. This weakened version of Normic Reliabilism can be expressed as follows.

Weak Normic Reliabilism (WNR) In order for $S$ to have justification for believing a proposition $\mathrm{P}$, it is necessary that $\mathrm{S}$ 's belief was reliably produced-it is necessary that (i) the belief that $\mathrm{P}$ was produced by a belief-forming method $\mathrm{M}$ that would not, in any normal world, have produced the belief that $\mathrm{P}$ if $\mathrm{P}$ were false and (ii) that the believer has no reason to believe that conditions are abnormal or if the believer has reason to believe that conditions are abnormal, it is reasonable to assume that the method remains highly reliable across modal space.

These weakened versions of the Normic Support Account and Normic Reliabilism are able to avoid the Easy-Defeat Problem. Consider for instance what (WNSA) and (WNR) would predict in Allergy. Despite the fact that Helen's evidence is compatible with a few normal worlds in which her brownie is contaminated and therefore not safe to eat, it will nevertheless remain the case that in nearly all E-worlds P is true. So, according to (WNSA) Helen's belief would be justified. Similar considerations apply to (WNR). Even though Helen has reason to believe that conditions are abnormal-after all one of the presuppositions that ensure her belief-forming method's perfect reliability across modal space has been violated-she also has reason to believe that her belief-forming method will remain 
highly reliable as the number of worlds in which she falsely believes that her brownie is safe to eat is very small. Analogous considerations apply in the case of Lightning. Given Helen's total evidence, her belief that she will see Bob next weekend, while not true in all normal worlds, will nevertheless be true in nearly all normal worlds. So, according to (WNSA) Helen would be justified in believing that she will see Bob next weekend. Again, similar considerations apply in the case of (WNR). Even though Helen has reason to believe that one of the presuppositions ensuring her belief-forming method's perfect reliability has been violated, she also has reason to believe that the method by which she came to believe that she will see Bob next weekend will remain highly reliable across modal space. So, according to (WNR) her belief will be justified. Thus, the weakened versions of the two accounts appear to deliver the intuitively correct results and avoid the Easy-Defeat Problem. However, while initially promising, there are good reasons for being suspicious of the weakened accounts.

(WNSA) and (WNR) essentially mark a return to a threshold conception of justification. An indication of this collapse into threshold views is the 'nearly all' quantifier in (WNSA) and the appearance of 'highly reliably' in (WNR). One consequence of this is that the weakened accounts are no longer instances of Normalcy Views - they betray (NT). A related second consequence is that like all threshold views (for $\mathrm{t}<1$ ), the weakened accounts face the problem of risk accumulation over conjunctions. This means that (WNSA) and (WNR), unlike their stronger counterparts, will not be compatible with (MPC). This is problematic because it was the promise of preserving (MPC) that was the primary motivation for the two accounts. Without preserving (MPC) the accounts become unmotivated.

It appears then that the Normic Support Account and Normic Reliabilism face a dilemma: The original accounts, which are committed to (NT), face the Easy-Defeat Problem, while the weaker versions, which by violating (NT) are able to avoid this problem, collapse back into threshold views and therefore cannot make good on their motivating promise of preserving (MPC). We may call this the Easy-Defeat Dilemma.

Besides putting pressure on the Normic Support Account and Normic Reliabilism, the above considerations also point towards a more general connection between Normalcy Views and the Easy-Defeat Problem. As we have seen, what gets the two leading Normalcy Views into trouble has little to do with any account-specificfeatures (e.g. their respective notions of normality) and everything to do with a more general feature of the views, namely their modal strength. Importantly, the modal strength of Normalcy Views is not merely an optional feature of the views but instead it is required to make good on the promise of preserving (MPC) - after all the problem of risk accumulation needs to be avoided. In other words, the modal strength of (NT), which is directly responsible for the Easy-Defeat Problem, is an essential feature of Normalcy Views of justification. As a result, we can expect the problem to generalize to any Normalcy View-i.e. to any account of justification committed to (NT) - regardless of how the details are developed. What does this mean for the general prospects of Normalcy Views? Well, in so far as we take seriously the idea that justification should be sufficiently robust and be able to 
survive small amounts of risk, we have good reasons to be skeptical about the success of Normalcy Views.

\section{Conclusion}

In this paper I have raised an objection against one broad family of non-probabilistic accounts of justification. I argued that Normalcy Views of justification, i.e. accounts of justification committed to (NT), whilst providing the perhaps most promising framework for preserving (MPC), face a serious problem when it comes to the notion of epistemic defeat.

First I showed that the two leading Normalcy Views-the Normic Support Account and Normic Reliabilism-give rise to what I called the Easy-Defeat Problem. Next I showed that the only way of avoiding this problem requires weakening the modal strength of the accounts, which ultimately led to a violation of (NT). Finally, I argued that there is little hope that other Normalcy Views will be able to avoid this problem. This pessimism is justified by the fact that the EasyDefeat Problem, as we have seen, is not an incidental feature of the Normic Support Account or Normic Reliabilism, but instead a more general, structural, problem resulting from Normalcy Views' modal strength.

Acknowledgements I would like to thank Patrick Greenough, Martin Smith, Matthew McGrath, Claire Field, the participants of the Work in Progress Seminar at St Andrews, and two anonymous referees for helpful comments on earlier versions of this paper.

Open Access This article is distributed under the terms of the Creative Commons Attribution 4.0 International License (http://creativecommons.org/licenses/by/4.0/), which permits unrestricted use, distribution, and reproduction in any medium, provided you give appropriate credit to the original author(s) and the source, provide a link to the Creative Commons license, and indicate if changes were made.

\section{References}

Alston, W. P. (1988). An internalist externalism. Synthese, 74(3), 265-283.

Anderson, C. (2017). Between probability and certainty: What justifies belief by Martin Smith. Analysis, 77(3), 670-672.

Bergmann, M. (2006). Justification without awareness: A defense of epistemic externalism. Oxford: OUP. BonJour, L. (1985). The structure of empirical knowledge. Cambridge, MA: Harvard University Press. Christensen, D. (2007). Three questions about Leplin's reliabilism. Philosophical Studies, 134(1), 43-50. Conee, E., \& Feldman, R. (2004). Evidentialism. Oxford: OUP.

Foley, R. (1992). The epistemology of belief and the epistemology of degrees of belief. American Philosophical Quarterly, 29(2), 111-124.

Goldman, A. (1979). What is justified belief? In G. Pappas (Ed.), Justification and knowledge (pp. 1-25). Boston, MA: D. Reidel.

Hawthorne, J. (2004). Knowledge and lotteries. Oxford: OUP.

Ichikawa, J. J. (2014). Justification is potential knowledge. Canadian Journal of Philosophy, 44(2), $184-206$.

Leplin, J. (2009). A theory of epistemic justification. Berlin: Springer.

Moser, P. K. (1989). Knowledge and evidence. New York, NY: Cambridge University Press. 
Nozick, R. (1981). Philosophical explanations. Cambridge, MA: Harvard University Press.

Plantinga, A. (1993). Warrant and proper function. Oxford: OUP.

Pritchard, D. (2005). Epistemic luck. Oxford: OUP.

Pryor, J. (2004). What's wrong with Moore's argument? Philosophical Issues, 14(1), 349-378.

Smith, M. (2010). What else justification could be. Nô̂s, 44(1), 10-31.

Smith, M. (2016). Between probability and certainty: What justifies belief. Oxford: OUP.

Sosa, E. (1999). How to defeat opposition to Moore. Philosophical Perspectives, 13, 137-149.

Sturgeon, S. (2008). Reason and the grain of belief. Noûs, 42(1), 139-165.

Swinburne, R. (2001). Epistemic justification. Oxford: OUP.

Vogel, J. (1990). Are there counterexamples to the closure principle? In M. D. Roth \& G. Ross (Eds.), Doubting: Contemporary perspectives on skepiticism (pp. 13-29). Dordrecht: Kluwer.

Vogel, J. (1999). The new relevant alternatives theory. Philosophical Perspectives, 13, 155-180.

Williamson, T. (2000). Knowledge and its limits. Oxford: OUP. 